\title{
Expression of the p53 Inhibitors MDM2 and MDM4 as Outcome Predictor in Muscle-invasive Bladder Cancer
}

\author{
MAXIMILIAN CHRISTIAN KRIEGMAIR ${ }^{1 *}$, MATTHIAS BALK ${ }^{1}$, RALPH WIRTZ ${ }^{2 *}$, \\ ANNETTE STEIDLER ${ }^{1}$, CLEO-ARON WEIS ${ }^{3}$, JOHANNES BREYER ${ }^{4 *}$, \\ ARNDT HARTMANN ${ }^{5 *}$, CHRISTIAN BOLENZ $^{6 *}$ and PHILIPP ERBEN ${ }^{1 *}$ \\ ${ }^{1}$ Department of Urology, University Medical Centre Mannheim, Mannheim, Germany; \\ ${ }^{2}$ Stratifyer Molecular Pathology, Köln, Germany; \\ ${ }^{3}$ Institute of Pathology, University Medical Centre Mannheim, Mannheim, Germany; \\ ${ }^{4}$ Department of Urology, University of Regensburg, Regensburg, Germany; \\ ${ }^{5}$ Institute of Pathology, University Erlangen-Nuernberg, Erlangen, Germany; \\ ${ }^{6}$ Department of Urology, University of Ulm, Ulm, Germany
}

\begin{abstract}
Aim: To evaluate the prognostic role of the p53upstream inhibitors MDM2, MDM4 and its splice variant MDM4-S in patients undergoing radical cystectomy $(R C)$ for muscle-invasive bladder cancer (MIBC). Materials and Methods: mRNA Expression levels of MDM2, MDM4 and MDM4-S were assessed by quantitative real-time polymerase chain reaction (qRT-PCR) in $75 R C$ samples. Logistic regression analyses identified predictors of recurrence-free (RFS) and cancer-specific survival (CSS). Results: High expression was found in 42\% (MDM2), 27\% (MDMD4) and 91\% (MDM4-S) of tumor specimens. Increased MDM2 expression was significantly associated with higher tumor stage $(p=0.05)$ and lymphovascular invasion (LVI) $(p=0.041)$. In the univariate analysis, low MDM4 expression ( hazard ratio $(H R)=5.93 ; p=0.002 ; H R=3.00 ; p=0.047)$, but not MDM2 (HR=1.63; $p=0.222 ; H R=1.59 ; p=0.27)$, were associated with RFS and CSS. In the multivariate analysis, the combination of low MDM4 and high MDM2 was significant for RFS and CSS (HR=14.9; $p=0.001 ; H R=5.63$; $p=0.019)$. Conclusion: The combination of MDM2 and MDM4 expression is an independent predictor in patients undergoing $R C$ for $M I B C$.
\end{abstract}

*On behalf of the BRIDGE Consortium.

Correspondence to: Maximilian Kriegmair, University Medical Centre Mannheim, Department of Urology, Theodor-Kutzer-Ufer 13, 68167 Mannheim, Germany. Tel: +49 6213831610, Fax: +49 6213831923, e-mail: maximilian.kriegmair@medma.uniheidelberg.de

Key Words: bladder cancer, MDM2, HDMX, marker, prognosis.
Urothelical cell carcinoma (UCC) of the bladder is the second most common urogenital neoplasm worldwide (1). Whereas non-muscle invasive UCC can be well treated and controlled by endoscopic resection, for MIBC, which represents $30 \%$ of tumor incidence, radical cystectomy $(\mathrm{RC})$ remains the only curative option. However, MIBC progresses frequently to a life-threatening metastatic disease with limited therapeutic options (2). Standard clinical prognosis parameters in bladder cancer such as stage, grade or patient's age, have limitations in assessing individual patient's prognosis and response to different treatment options.

Recently, gene expression profiling of UCC has identified patterns of gene signatures that can help predict outcome and clinical stage or even select patients for systemic therapies (3, 4). Amongst others, the tumor suppressor p53 has been suggested to be a possible predictor of survival and chemoresistance (5). In accordance, mutations or altered gene expression of $p 53$ have been found in the majority of all human cancer forms, making it a key player in tumor genesis and evolution $(6,7)$. Many studies on UCC of the bladder have concentrated on p53 mutational status and its downstream targets, while proteins regulating p53 activity are less studied (6). The ubiquitin ligase human mouse double minute 2 (MDM2, HDM2) acts as a cell-cycle regulator by degradation of p53. MDM2 gene or MDM2 protein alterations can be found in several human cancer types (8). In bladder cancer the mutational variant MDM2 SNP309 has been investigated with varying results. Whereas previous studies found and increased tumor risk and poorer overall survival for superficial cancers in cases expressing the wild type, more recently, it has been shown that a mutational variant is associated with the formation of a more aggressive tumor form (9). HDMX (MDM4) is a close homologue of MDM2 that suppresses $p 53$ transcription and has analogously 
been connected to oncogenesis $(10,11)$. Tumor cells show an altered activity, particularly when $p 53$ wild type is retained (12). Consequently, MDM4 has recently been brought into play as a possible therapeutic target (13). Although one study associated gene amplification of MDM4 with low recurrence risk in muscle-invasive bladder cancer (MIBC), its role as a potential marker or therapeutic target for UCC of the bladder remains unresolved (14). Furthermore, the ratio of $M D M 4$ and an alternative splice variant, namely $M D M 4-S$ (exclusion of exon 6), was found to be associated with higher grade at diagnosis and a decreased overall survival (OS) in different tumors (15-17). Most recently the ratio of MDM4 and $M D M 4-S$ was declared a superior prognostic biomarker than p53 in soft tissue sarcoma (11).

The aim of this study was to evaluate the role of $M D M 2$, $M D M 4$ and MDM4-S as novel prognostic markers for disease stage and survival in patients with muscle-invasive UCC of the bladder treated with RC. To overcome the limitations of immunohistochemistry-based marker evaluation, being -in particular- its semi-quantitative, non-standardized and subjective interpretation, we employed a quantitative realtime polymerase chain reaction (qRT-PCR)-based assessment of the markers' expression in the respective tumor samples.

\section{Patients and Methods}

Patient population and cell lines. The study was approved by the Institutional Ethical Committee (2013_834R-MA). We included patients treated with $\mathrm{RC}(\mathrm{T} 1-4, \mathrm{Nx})$ and bilateral lymphadenectomy (obturator fossa, external and internal iliac region) for MIBC at our institution between 1998 and 2006. Patients who received neoadjuvant chemotherapy were excluded. Tumor tissue samples were obtained retrospectively and clinical records were assessed for clinical and pathological data.

The human urothelial carcinoma cell lines UMUC-3 and RT-112 (ATCC ${ }^{\circledR}$, obtained from LGC Standards, Rockville, MD, USA) were cultured under standard conditions. RNA from serial diluted cell lines were used to analyze assay linearity and precision (Inter,Intra-run variation).

Pathological evaluation. After intraoperative frozen section of ureteric and urethral resection edges, tissue was fixed in formaldehyde. Fixation of tumor specimens followed standard protocols, using either $10 \%$ non-buffered or $10 \%$ buffered formalin. Storage time of the archival samples was up to 15 years at room temperature. Hematoxylin-eosin stained sections were evaluated for pathological stage according to the 2002 TNM classification of the American Joint Committee on Cancer and tumor grade according to the 1998 WHO/International Society of Urologic Pathology consensus classification.

RNA isolation. RNA isolation from formalin-fixed, paraffinembedded (FFPE) tissue was performed as described before $(18,19)$. Tumor sustaining areas were identified by uro-pathologists and exclusively used for RNA extraction respectively to avoid mixture with non-malignant tissue. One $10-\mu \mathrm{m}$-thick section was used isolation of RNA according to a fully automated, high-throughput
Table I. Characteristics of 75 patients undergoing radical cystectomy.

\begin{tabular}{lcc}
\hline & n or median & Percentage/range \\
\hline Age, years & 66.1 & $39-84$ \\
$\geq 75$ & 13 & 17.3 \\
$<75$ & 62 & 82.7 \\
Gender & & \\
Male & 57 & 76.0 \\
Female & 18 & 24.0 \\
Tumor stage & & \\
pTa & 1 & 1.3 \\
pT1 & 1 & 1 \\
pT2 & 21 & 28.0 \\
pT3 & 40 & 53.3 \\
pT4 & 13 & 14.6 \\
CIS & 1 & 1.3 \\
Grading & & \\
low-grade & 12 & 16.0 \\
high-grade & 63 & 84.0 \\
Concomitant carcinoma in situ & 7 & 9.33 \\
Nodal stage & & \\
pN0 & 42 & 56.0 \\
pN1 & 7 & 9.3 \\
pN2 & 23 & 30.6 \\
Lymphovascular invasion & 41 & 0.54 \\
Positive margins & 7 & 9.3 \\
Recurrence & 31 & 0.41 \\
Time to recurrence, months & 32.3 & $3.6-180.8$ \\
Cancer-specific death & 22 & 29 \\
Time to cancer-specific death & 11.5 & $4.5-128.1$ \\
\hline
\end{tabular}

extraction workflow that runs on an Xtract XL liquid-handling robot (STRATIFYER Molecular Pathology GmbH, Cologne, Germany). The extraction solutions and chemicals are commercially available in Germany as part of the XTRAKT FFPE kit, which is based on magnetic bead technology (STRATIFYER). In brief, FFPE sections were solubilized and paraffin was melted by incubating with a lysis buffer in a Thermo-mixer. Tissue was lyzed with Proteinase K. The lysates were then admixed with germanium-coated magnetic particles in buffer-controlled conditions that enhance preferential attachment of nucleic acid molecules to the surface of the particles. Purification was carried out by means of 3 consecutive washing cycles involving magnetization, centrifugation, washing and removal of the supernatant. Nucleic acids were eluted with $100 \mu$ l elution buffer and treated with DNase I. The DNA-free RNA eluates were stored at $-80^{\circ} \mathrm{C}$ until use. RNA was reversely transcribed using the sequence specific primers and Super Script III reverse transcriptase (Thermo Fisher Scientific, Waltham, MA, USA).

Total RNA form cell lines was extracted using RNeasy Mini Kit (Qiagen, Hilden, Germany) according to the manufacturer's instructions. RNA was reversely transcribed using random hexamer priming and MMLV reverse transcriptase (Thermo Fisher Scientific).

Quantitative real-time polymerase chain reaction. QRT-PCR was applied for the relative quantification of MDM2, MDM4 and MDM4-S mRNA expression by using gene-specific TaqMan ${ }^{\circledR}$-based assays. Expression levels of the target genes, as well as of the reference gene Calmodulin 2 (CALM2) (20), were assessed in 
triplicates by qRT-PCR using the SuperScript III PLATINUM OneStep, quantitative RT-PCR System (Invitrogen, Karlsruhe, Germany) on a StepOnePlus Real-Time PCR System (Thermo Fisher) with 30 min at $50^{\circ} \mathrm{C}, 2 \mathrm{~min}$ at $95^{\circ} \mathrm{C}$ followed by 40 cycles of $15 \mathrm{~s}$ at $95^{\circ} \mathrm{C}$ and $30 \mathrm{~s}$ at $60^{\circ} \mathrm{C}$. Urothelial carcinoma cell lines (RT112, UMUC) were used as positive controls. Forty cycles of nucleic acid amplification were applied and the cycle threshold $(\mathrm{Ct})$ values of the target genes were identified. Ct values were normalized by subtracting the $\mathrm{Ct}$ value of the housekeeping gene CALM2 from the $\mathrm{Ct}$ value of the target genes $(\Delta \mathrm{Ct})$. RNA results were then reported as $40-\Delta \mathrm{Ct}$ values, which correlate proportionally with the mRNA expression level of the target genes. The quantity of RNA following isolation (yield) was determined by measuring CALM2 expression as a surrogate marker for amplifiable mRNA. Samples with average $C A L M 2 \mathrm{Ct}$ values $<30$ were considered to have sufficient RNA and were eligible for further analysis.

The following probe/primer sets were used:

\begin{tabular}{|c|c|c|}
\hline Primer/Probe & Sequence & $\begin{array}{l}\text { Annealing } \\
\text { temperature }\end{array}$ \\
\hline MDM2 Forward & $\begin{array}{l}\text { GGGAGATATGTTGTGAAA } \\
\text { GAAGC }\end{array}$ & $58.9^{\circ} \mathrm{C}$ \\
\hline MDM2 Reverse & $\begin{array}{l}\text { GGATCAGGATTCAGTTTC } \\
\text { AGATC }\end{array}$ & $58.9^{\circ} \mathrm{C}$ \\
\hline MDM2 Probe* & $\begin{array}{l}\text { GCCATCGAATCCGGATCT } \\
\text { TGATGCTGGTG }\end{array}$ & $69.5^{\circ} \mathrm{C}$ \\
\hline MDM4 Forward & CTACTGGGACGTCAGAGCTTC & $61.8^{\circ} \mathrm{C}$ \\
\hline MDM4 Reverse & CACTGCTACTACAGGATGCCA & $59.8^{\circ} \mathrm{C}$ \\
\hline$M D M 4-S$ Forward & CTACTGGGACGTCAGAGCTTC & $61.8^{\circ} \mathrm{C}$ \\
\hline MDM4-S Reverse & GCTGCTCAGACTCTCGCTCT & $61.4^{\circ} \mathrm{C}$ \\
\hline MDM4 Probe* & $\begin{array}{l}\text { CCGTGAAAGACCCAAGCCCT } \\
\text { CTCTATGATAT }\end{array}$ & $68.2^{\circ} \mathrm{C}$ \\
\hline CALM2 Forward & GAGCGAGCTGAGTGGTTGTG & $61.4^{\circ} \mathrm{C}$ \\
\hline CALM2 Reverse & AGTCAGTTGGTCAGCCATGCT & $59.8^{\circ} \mathrm{C}$ \\
\hline CALM2 Probe** & TCGCGTCTCGGAAACCGGTAGC & C $65.8^{\circ} \mathrm{C}$ \\
\hline
\end{tabular}

*yak_BBQ2 labeled, **fam-BBQ2 labeled.

Statistical analysis. Associations between gene expression values of patients and histopathological data were calculated using the Mann Whitney test. Cut-off definitions for gene expression were done by Partitioning tests analysis. Univariable Cox proportional hazard models addressed clinical and pathological parameters, as well as recurrence-free (RFS) and cancer-specific survival (CSS). Significant markers from the univariate analysis were calculated with the logrank test and graphically shown as Kaplan-Meier plots. Multivariate logistic regression was performed controlling for all significant parameters of the univariate analysis to identify independent predictors for RFS and CSS. All tests were performed two-sided and a $p<0.05$ was considered to be statistically significant. All statistical analyses were performed using SAS JMP 10.0 (SAS, Cary, NC, USA) and GraphPad Prism 5 (GraphPad Software, La Jolla, CA, USA).

\section{Results}

Overall, 114 patients treated with $\mathrm{RC}$ for MIBC in a transurethral resection specimen were identified and respective tissue samples were obtained. Sufficient tissue or RNA quality was found in 75 patients who were included into further analysis. The median follow-up of this study population was 36.8 (range $=1.1-181)$ months. None of the patients underwent neo-adjuvant chemotherapy, whereas $12.0 \%$ (9 patients) received adjuvant systemic treatment (cisplatin/gemcitabine). Clinical and pathological characte-ristics of the population are listed in Table I. Pathological reports revealed pT3/4 tumors for $57(70.6 \%)$ cases and 7 (9.3\%) patients had a concomitant carcinoma in situ. Approximately half of the patients $(n=42$, $56 \%$ ) had no lymphatic metastasis, whereas $30.6 \%$ showed a nodal stage $>$ pT1. A recurrence was noted in 31 cases $(41.0 \%)$ and occurred in median 32.2 (2.6-180.8) months after RC. Cancer-specific death was noted in 22 cases (29.0\%) after 11.5 (4.5-128.1) months.

The inter- and intra-assay variations of the applied assays were calculated by repeated analyses of a bladder carcinoma cell lines UMUC and RT112. The standard deviation (SD) for the intra-assay variation was between $0.11-0.3 \mathrm{Ct}$ and between $0.25-0.6 \mathrm{Ct}$ for the inter-assay variation. All assays were linear over five orders of magnitudes, as assessed by cell line dilutions up to $\mathrm{Ct}$ values between 33.5 and 37.0. Amplification efficiencies ranged from 94 to $104 \%$.

Figure 1A illustrates the normalized mRNA gene expression in the tumor of the study population. The median normalized expression of MDM2 was 35.2, of MDM4 35.1 and of MDM4$S$ 36.6. All genes are similarly distributed, whereas overall $M D M-4 S$ expression was significantly higher than $M D M 2$ and MDM4 (MDM2 versus MDM4-S $p=0.009$ and median MDM4 versus $M D M 4-S p<0.001)$. Expression levels of all genes significantly correlated with the other respective markers, whereas strongest correspondence was found for MDM4 and its splice variant: MDM2 - MDM4; r=0.3021, $p=0.0349$; MDM2 - MDM4-S; $r=0.5221, p<0.0001$; MDM4 - MDM4$\mathrm{S} ; \mathrm{r}=0.8420, p<0.0001$. Figure $1 \mathrm{~B}$ shows the results of the partitioning tests with the highest predictive value for cancerspecific survival. High $M D M 2$ expression (cut-off=33.8) was found in 42\% (31) and high MDM4 expression (cut-off=35.6) in 27\% (20) of the tumors. The splice variant MDM4-S revealed a high expression (cut-off $=37.7$ ) in the majority $(91 \%, 68)$ of the cases. Due to the uneven distribution, the median of 36.6 was used for further analysis.

Table II illustrates expression of MDM2, MDM4 and MDM4-S with regard to different clinicopathological parameters of the study population. A significantly higher expression of $M D M 2$ was found in patients with higher tumor stage (pT3/4, 33.8 vs. 35.7, $p=0.05)$ and lymphovascular invasion (33.8 vs. 35.5, $p=0.041)$. No significant association between MDM4 expression and clinicopathological characteristics was observed, whereas MDM4-S expression was higher in patients with advanced nodal stage (pN2, 36.5 vs. 37.1, $p=0.018)$.

The log-rank tests identified high MDM4 expression to be significantly associated with an improved RFS 

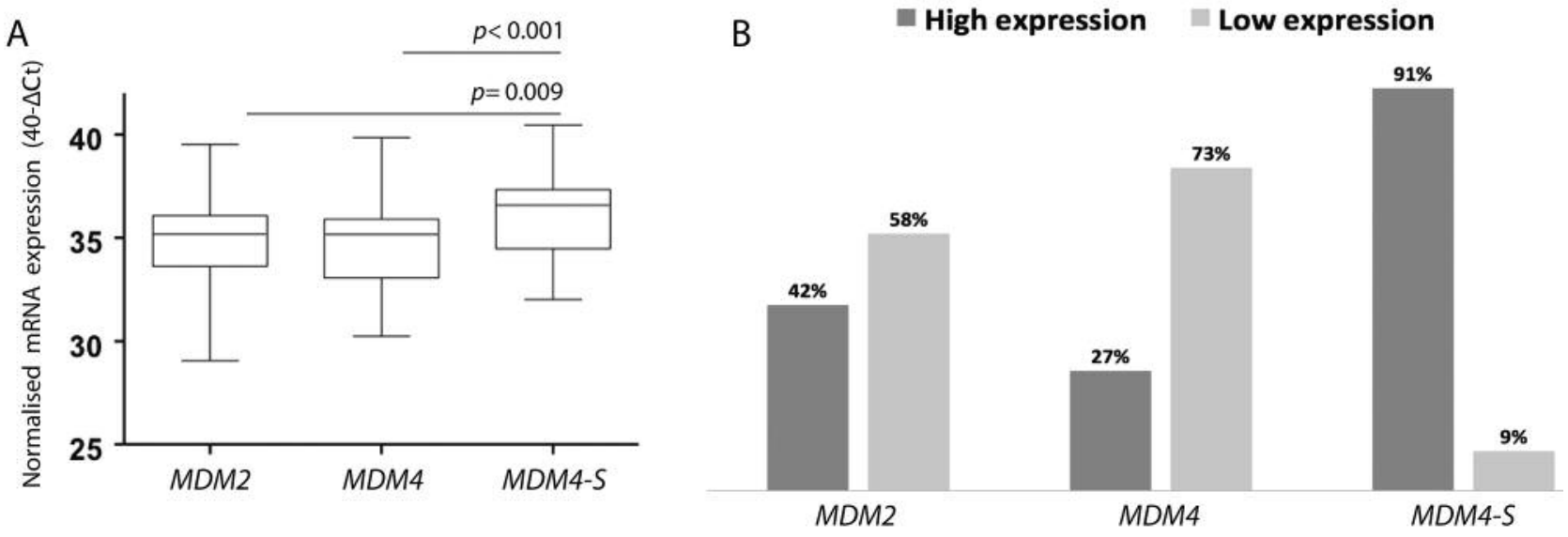

Figure 1. Expression of MDM2, MDM4 and MDM4-S. A: Distribution of normalized mRNA expression values in analyzed cystectomy specimens. mRNA gene expression of MDM4-S was significantly higher in comparison with gene expression of the two wild type genes. B: Percentage of tumors with high and low mRNA gene expression. Box and whisker plots are from minimum to maximum, gene expression values were compared by two-way MannWhitney test. The cut-offs with the highest predictive stratification for cancer-specific survival (CSS) were defined using the partitioning test.

$(p=0.0062)$. Patients with high expression of MDM4 showed a RFS of 60 months in $87 \%$ of the cases, whereas only $42 \%$ of patients with low MDM4 revealed no recurrence at this time. For CSS, there was a trend towards significance $(p=0.065)$. The percentage of patients with 60 months CSS were $81 \%$ and $55 \%$, respectively. For MDM2 and MDM4-S expression, no significant differences regarding RFS and CSS were observed in the Kaplan-Meier analysis and log-rank test (data not shown). We further divided the patient group with low MDM4 expression regarding to their expression of $M D M 2$. For patients with low MDM4 and high MDM2 expression (MDM2/MDM4) in the cystectomy tumor specimen, RFS $(p=0.0006)$ and CSS $(p=0.0255)$ were particularly impaired. This group revealed a RFS over 60 month in $10 \%$ of the cases and a CSS over 60 month in $41 \%$ of the cases. The respective Kaplan-Meier curves are illustrated in Figure 2.

The results of the regression analysis for RFS and CSS are presented in Table III. Pathological tumor stage (hazard ratio $(\mathrm{HR})=2.96, p=0.017)$, positive nodal stage $(\mathrm{HR}=4.48$, $p=0.003)$, low expression of MDM4 (HR=5.93, $p=0.002)$, as well as the combination of high MDM2 and low MDM4 expression stage (HR=10.41, $p=0.001)$, were significantly associated with reduced RFS. Similar results were obtained for CSS: Pathological tumor stage $(\mathrm{HR}=3.54, p=0.046)$, positive nodal stage $(\mathrm{HR}=3.54, p=0.006), M D M 4(\mathrm{HR}=3.00$, $p=0.047)$ and $M D M 2 / M D M 4(\mathrm{HR}=2.86, p=0.01)$. For $M D M 2$ and MDM4-S, no significant association was found for RFS and CSS. The multivariate analysis identified nodal stage and $M D M 4 / M D M 2$ to be independent predictors for RFS and CSS (HR=14.9, $p=0.001 ; \mathrm{HR}=5.63, p=0.019$ ).
Table II. Association between clinicopathological characteristics and marker expression.

\begin{tabular}{|c|c|c|c|c|c|c|}
\hline & \multicolumn{2}{|c|}{$M D M 2$} & \multicolumn{2}{|c|}{$M D M 4$} & \multicolumn{2}{|c|}{$M D M 4-S$} \\
\hline & Median & $p$-Value & Median & $p$-Value & Median & $p$-Value \\
\hline \multicolumn{7}{|l|}{ Age, years } \\
\hline$\geq 75$ & 33.9 & 0.123 & 34.5 & 0.331 & 35.2 & 0.095 \\
\hline$<75$ & 35.3 & & 35.2 & & 36.6 & \\
\hline \multicolumn{7}{|l|}{ Gender } \\
\hline Male & 35.7 & 0.578 & 35.1 & 0.379 & 36.5 & 0.012 \\
\hline Female & 35.8 & & 36.1 & & 37.4 & \\
\hline \multicolumn{7}{|l|}{ Tumor stage } \\
\hline $\mathrm{pT} 2$ & 33.8 & 0.05 & 35.6 & 0.52 & 36.2 & 0.35 \\
\hline $\mathrm{pT} 3 / 4$ & 35.7 & & 35.0 & & 36.7 & \\
\hline \multicolumn{7}{|l|}{ Grading } \\
\hline G2 & 33.9 & 0.41 & 34.2 & 0.62 & 33.7 & 0.10 \\
\hline $\mathrm{G} 3 / 4$ & 35.2 & & 35.2 & & 36.6 & \\
\hline Concomitant & 34.7 & 0.52 & 35.5 & 0.17 & 36.7 & 0.64 \\
\hline carcinoma in situ & 35.3 & & 35.3 & & 36.5 & \\
\hline \multicolumn{7}{|l|}{ Nodal stage } \\
\hline pN0 & 34.9 & 0.17 & 34.9 & 0.26 & 36.5 & 0.018 \\
\hline $\mathrm{pN} 2$ & 35.8 & & 35.4 & & 37.1 & \\
\hline pNO & 34.9 & 0.30 & 34.9 & 0.47 & 36.5 & 0.17 \\
\hline $\mathrm{pN} 1 / \mathrm{pN} 2$ & 35.5 & & 35.4 & & 36.8 & \\
\hline \multicolumn{7}{|l|}{$\begin{array}{l}\text { Lymphovascular } \\
\text { invasion }\end{array}$} \\
\hline L0 & 33.8 & 0.041 & 34.9 & 0.48 & 36.6 & 0.52 \\
\hline L1 & 35.5 & & 35.3 & & 36.6 & \\
\hline
\end{tabular}

Significant values are given in bold. 
Table III. Cox regression for recurrence-free and cancer-specific survival.

\begin{tabular}{|c|c|c|c|c|c|c|c|c|}
\hline \multirow[b]{3}{*}{ Age, years } & \multicolumn{4}{|c|}{$\begin{array}{c}\text { Univariate } \\
\text { Recurrence-free survival }\end{array}$} & \multicolumn{4}{|c|}{ Multivariate } \\
\hline & \multirow{2}{*}{$\begin{array}{l}\text { HR } \\
1.94\end{array}$} & \multicolumn{2}{|r|}{$95 \%-\mathrm{CI}$} & \multirow{2}{*}{$\frac{p \text {-Value }}{0.182}$} & \multirow[t]{2}{*}{$\mathrm{HR}$} & \multicolumn{2}{|c|}{$95 \%-\mathrm{CI}$} & \multirow[t]{2}{*}{$p$-Value } \\
\hline & & 0.71 & 4.59 & & & & & \\
\hline Tumor-stage & 2.96 & 1.20 & 8.91 & 0.017 & 2.51 & 0.12 & 1.08 & 0.07 \\
\hline Nodal Stage & 4.48 & 2.02 & 10.21 & 0.003 & 7.55 & 2.90 & 21.34 & 0.001 \\
\hline Grading & 1.94 & 0.57 & 12.06 & 0.324 & & & & \\
\hline LVI & 2.05 & 0.86 & 5.32 & 0.103 & & & & \\
\hline High $M D M 2$ & 1.63 & 0.73 & 3.53 & 0.222 & & & & \\
\hline Low $M D M 4$ & 5.93 & 1.74 & 37.04 & 0.002 & & & & \\
\hline High $M D M 4-S$ & 1.12 & 0.48 & 3.87 & 0.742 & & & & \\
\hline \multirow[t]{3}{*}{$M D M 4 / M D M 2$} & 10.41 & 2.88 & 67.11 & 0.001 & 14.94 & 3.66 & 104.12 & 0.001 \\
\hline & \multicolumn{4}{|c|}{ Cancer-specific survival } & & & & \\
\hline & HR & & $95 \%$-CI & $p$-Value & HR & & & $p$-Value \\
\hline Age & 1.01 & 0.96 & 1.05 & 0.79 & & & & \\
\hline Tumor-stage & 2.75 & 1.01 & 9.62 & 0.05 & 1.63 & 0.51 & 6.36 & 0.42 \\
\hline Nodal Stage & 3.54 & 1.45 & 8.71 & 0.006 & 3.97 & 1.47 & 11.19 & 0.006 \\
\hline Grading & 1.32 & 0.44 & 5.68 & 0.64 & & & & \\
\hline LVI & 1.63 & 0.66 & 4.37 & 0.28 & & & & \\
\hline High $M D M 2$ & 1.59 & 0.68 & 3.37 & 0.27 & & & & \\
\hline Low MDM4 & 3.00 & 1.01 & 12.85 & 0.05 & & & & \\
\hline High $M D M 4-S$ & 1.14 & 0.51 & 2.73 & 0.74 & & & & \\
\hline$M D M 4 / M D M 2$ & 2.86 & 1.14 & 7.75 & 0.01 & 5.63 & 1.62 & 26.83 & 0.019 \\
\hline
\end{tabular}

HR, Hazard ratio; CI, confidence interval. Significant values are given in bold.

\section{Discussion}

Identifying distinct molecular subtypes of UCC of the bladder is highly anticipated to improve risk stratification and provide individual therapy regimens in the future. The tumor suppressor p53 has been assessed as a potential predictor of survival and chemoresistance. Recently, a "p53-like" subtype has been suggested and seems to go along with improved prognosis, but resistance to chemotherapy (21). Moreover, studies found p53 to be an independent predictor of clinical stage and recurrence, as well as a marker for invasiveness $(22,23)$. Since a mutational status correlates with unfavorable response to systemic therapy and poor outcome, the value of its upstream regulators as prognostic markers and possible therapeutic targets has newly met interest not only in UCC $(11,13)$. The aim of our work was, therefore, to analyze the predictive role of p53 upstream regulators in patients with MIBC. Acknowledged regulators of p53 activity are MDM2 and MDM4.

Although intensively studied, the role of p53 seems to be not conclusively clarified (24). This accounts for the inconsistent findings in studies assessing p53 expression with immunohistochemistry due to lack of standardization and lack of objectiveness $(7,24)$. Therefore, expression, in our study, was analyzed by qRT-PCR on mRNA level as objective, reproducible and sensitive tool for measuring expression levels and to enable transferability and comparison to other cohorts.

Especially in patients with UCC of the bladder, there have been diversified results found for the importance of MDM2 and $M D M 4$ expression $(9,14)$. While most studies on p53 upstream inhibitors in UCC examined tissue from nonmuscle invasive tumors, we analyzed the expression of $M D M 2$ and MDM4 and its splice variant MDM4-S in a cohort of patients treated with RC for MIBC. We showed that $M D M 2$ and MDM4 are highly expressed in tumor tissue and that MDM4 expression is associated with prolonged RFS and CSS, whereas MDM2 is associated with adverse pathological characteristics. The combination of both markers was an independent predictor for RFS and CSS.

Although MDM2 and MDM4 are close homologues, they seem to act differently on p53 regulation. Studies in mice suggest divergent mode of p53 control (25) and there exist data for an inverse relationship concerning protein expression reported and a higher expression in high-grade tumors (26). 


\section{Recurrence-free survival}
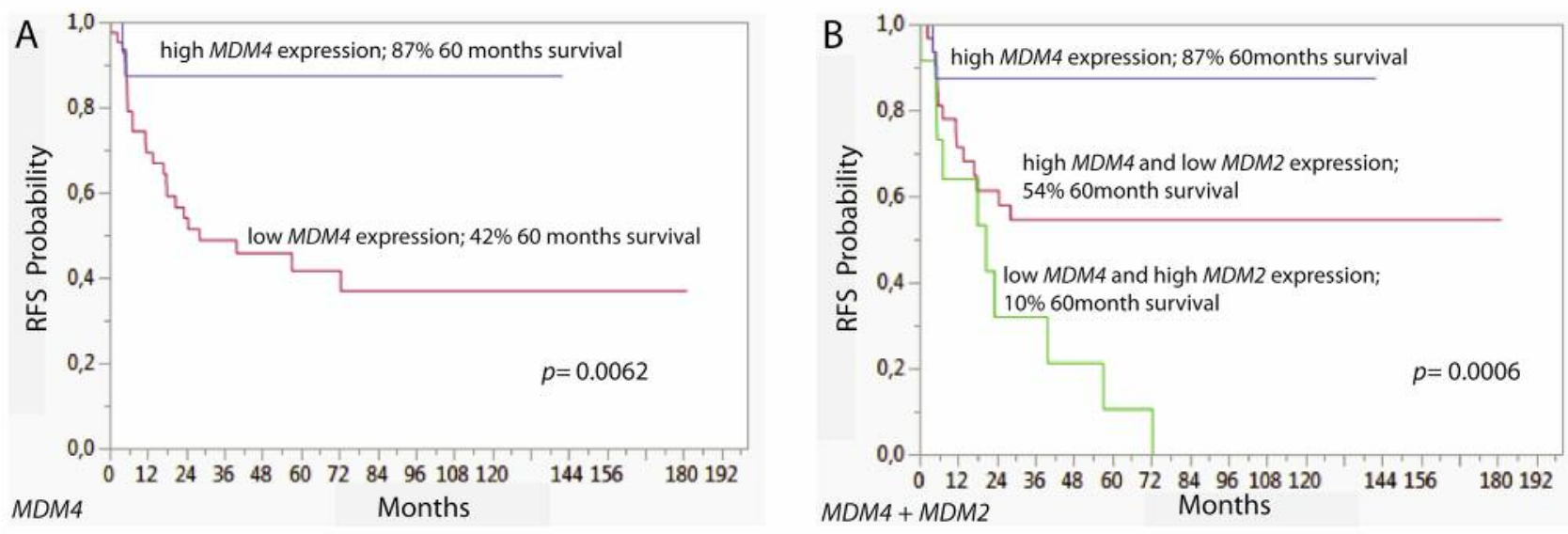

\section{Cancer-specific survival}
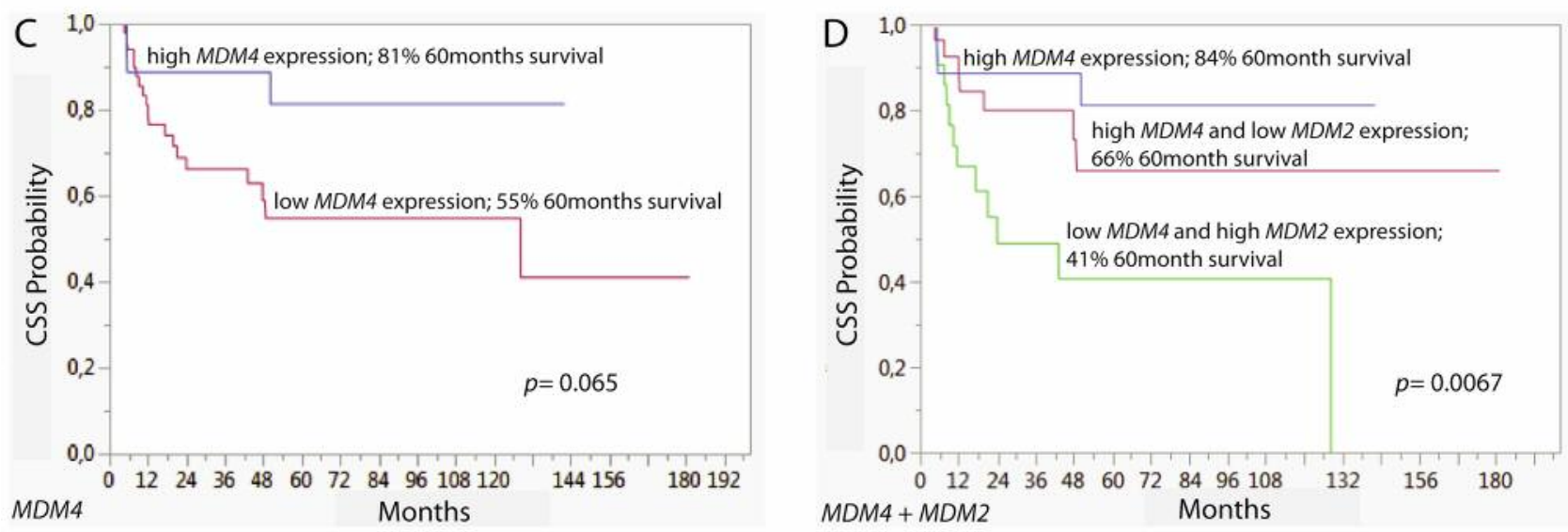

Figure 2. Survival analyses based on MDM4 and MDM2 expression. A: Kaplan-Meier curves of recurrence-free survival (RFS) stratified according to MDM4 mRNA expression. Five-year RFS for high MDM4 expression was 87\% and for low expression 42\%; $p=0.0062$. B: Kaplan-Meier curves of RFS stratified according to MDM4 and MDM2 mRNA expression. Five-year RFS for high MDM4 expression was between 87\%, for high MDM4 expression and 10\% for low MDM4 and high MDM2 expression; $p=0.065$. C: Kaplan-Meier curves of cancer-specific survival (CSS) stratified according to MDM4 mRNA expression. Five-year CSS for high MDM4 expression was $81 \%$ and for low expression 55\%; $p=0.0062$. D: KaplanMeier curves of CSS stratified according to MDM4 and MDM2 mRNA expression. Five-year CSS for high MDM4 expression was between 84\%, for high MDM4 expression and 41\% for low MDM4 and high MDM2 expression; $p=0.0067$.

More recent data, however, support the idea that both proteins are required to sufficiently inhibit p53 activity by formation of heterodimers $(27,28)$. The present study shows a similar expression of both genes in the examined tumors. Although not very strong, the correlation of the expression levels was significantly positive, which is contrary to the previously described inverse relationship. This can be explained, in part, by the variances in the applied analysis techniques and differences in analyzed cohorts. However, despite the positive relationship, high $M D M 2$ expression showed a trend towards poorer outcome and was associated with adverse pathological findings, such as higher tumor stage or LVI. MDM4 expression, on the other hand, was significantly associated with improved prognosis. The inverse combination of MDM2 and MDM4 expression was found to be an independent predictor of RFS and CSS. This could be a hint that both proteins act inversely in controlling $p 53$ and tumor activity.

MDM2 is a key regulator of the p53 pathway by directly mediating its degradation via the ubiquitination system (13). An increased expression of MDM2 mainly due to gene amplification is found in various malignancies, including $\operatorname{UCC}(8,9)$. A single nucleotide polymorphism (SNP) in the promoter region of the $M D M 2$ gene results in a more effective activation of transcription and, hence, higher mRNA 
and protein expression (29). The role of this SNP was studied in UCC of the bladder with inconsistent findings (9). Recently, it has been suggested that patients carrying the SNP might reveal a more aggressive form of bladder cancer without increasing overall tumor risk (9), while the influence on prognosis and recurrence rate is still debatable $(30,31)$. In the present series, an increased $M D M 2$ expression was found in patients with higher tumor stage and in tumors with LVI, while it did not seem to have an influence on prognosis. This mirrors the findings observed for the SNP in previous studies, although it remains unsolved whether an enhanced transcription due to the SNP or a gene amplifications led to a higher mRNA level in the present cohort. Contradictory to our findings and the fact that the more active form of the SNP causes a more invasive tumor form, there are studies that observed a better prognosis and lower tumor stage for tumors with high $M D M 2$ expression $(32,33)$. Up to date, the role of MDM2 expression in bladder cancer remains unsolved. Further studies contemporaneously regarding p53 mutational status and expression might help to further clarify this issue.

Unlike MDM2 expression, MDM4 was found to be a prognostic marker for RFS and CSS in this study. These findings are in accordance with the results of a copy number analysis of 24 oncogenes by Salvi and colleagues who found MDM4 amplification to be associated with reduced risk of recurrence of NMIBC (14). Opposing to this observation is the fact that MDM4 has been shown to negatively regulate p53 by inhibiting its transcription and indirectly by modulating MDM2 function (13). An impaired p53 activity due to an increased MDM4 activity should consequently rather result in tumor progression and poor outcome, as it has been shown for other malignancies $(13,16)$. There are two possible explanations why in UCC of the bladder high MDM4 expression/amplification seems to be associated with improved prognosis despite its role as putative oncogene. Firstly, array comparative genomic hybridization has been shown in a cohort of UCC that MDM4 amplification and mutations of p53 are mutually exclusive, suggesting that MDM4 overexpression is mainly found in tumors expressing wild type p53. Consequently, the effect of MDM4 overexpression due to gene amplification has been proposed as alternative tumorigenic way of escaping p53 tumor suppressor activity (26). Support for this hypothesis comes from breast cancer (34). In accordance with the findings of Salvi et al., this study suggests that the possible avoidance of p53 tumor suppression leads to a less aggressive tumor form. The second explanation why increased MDM4 expression goes along with improved prognosis is that MDM4 acts as tumor suppressor in cells with mutated and deficient p53 as previously suggested $(11,35,36)$. Although the mechanisms are still to be clarified, this study supports the findings that a higher expression of MDM4 is accompanied by improved prognosis. Although in UCC high MDM4 expression seems to be associated with improved outcome, its value as a possible therapeutic target may not be disregarded since it could be employed to reactivate wild-type p53 activity (28).

In addition to MDM4 wild type transcript, we further analyzed the expression of its splice variant $M D M 4-S$. Recently, the ratio of MDM4-S/MDM4 has been investigated in sarcoma, glioblastoma and breast cancer and it was shown that an increased ratio was associated with faster metastatic progression $(11,15)$. Lenos et al. further observed that MDM4 protein decreased in tumor cells mainly expressing the splice variant, suggesting that the MDM4-S protein is unstable or even inefficiently translated (11). In contrast, we observed a strong correlation between the expression of MDM4 and MDM4-S in the present series. However, despite its high expression, MDM4$S$ did not show any correlation with tumor characteristics and outcome leaving its putative role in UCC unresolved.

One limitation of the current study is its retrospective design with data originating from a single-center. However, it contributes to the molecular subclassification of UCC and helps clarify the role of p53 upstream regulators. It identified a marker combination as independent predictor for outcome in patients with MIBC. To confirm and verify the combination of $M D M 2$ and $M D M 4$ expression as possible predictor for outcome validation is required in a prospective multi-center approach. Furthermore, its predictive value of therapy response needs evaluation.

\section{Conclusion}

The current study show that MDM4 expression is a possible prognostic marker for patients with MIBC undergoing RC. MDM2 correlates with adverse pathological findings. Patients with low MDM4 and high MDM2 expression revealed an explicitly decreased RFS and CSS and the MDM2/MDM4 combination was identified as an independent predictor for outcome.

\section{References}

1 Parkin DM, Bray F, Ferlay J and Pisani P: Global cancer statistics, 2002. CA: A Cancer Journal for Clinicians 55: 74-108, 2005.

2 Shah JB, McConkey DJ and Dinney CPN: New strategies in muscle-invasive bladder cancer: on the road to personalized medicine. Clin Cancer Res 17: 2608-2612, 2011.

3 Sjödahl G, Lövgren K, Lauss M, Patschan O, Gudjonsson S, Chebil G, Aine M, Eriksson P, Månsson W, Lindgren D, Fernö M, Liedberg F and Höglund M: Toward a molecular pathologic classification of urothelial carcinoma. Am J of Pathol 183: 681691, 2013.

4 Lindgren D, Frigyesi A, Gudjonsson S, Sjodahl G, Hallden C, Chebil G, Veerla S, Ryden T, Mansson W, Liedberg F and Hoglund M: Combined gene expression and genomic profiling define two intrinsic molecular subtypes of urothelial carcinoma and gene signatures for molecular grading and outcome. Cancer Res 70: 3463-3472, 2010 
5 Choi W, Porten S, Kim S, Willis D, Plimack ER, HoffmanCensits J, Roth B, Cheng T, Tran M, Lee I-L, Melquist J, Bondaruk J, Majewski T, Zhang S, Pretzsch S, Baggerly K, Siefker-Radtke A, Czerniak B, Dinney CPN and McConkey DJ: Identification of distinct basal and luminal subtypes of muscleinvasive bladder cancer with different sensitivities to frontline chemotherapy. Cancer Cell 25: 152-165, 2014.

6 Lenos K, Grawenda AM, Lodder K, Kuijjer ML, Teunisse AFAS, Repapi E, Grochola LF, Bartel F, Hogendoorn PCW, Wuerl P, Taubert H, Cleton-Jansen A-M, Bond GL and Jochemsen AG: Alternate splicing of the p53 inhibitor HDMX offers a superior prognostic biomarker than p53 mutation in human cancer. Cancer Res 72: 4074-4084, 2012.

7 Stadler WM, Lerner SP, Groshen S, Stein JP, Shi S-R, Raghavan D, Esrig D, Steinberg G, Wood D, Klotz L, Hall C, Skinner DG and Cote RJ: Phase III study of molecularly targeted adjuvant therapy in locally advanced urothelial cancer of the bladder based on p53 status. J Clin Oncol 29: 3443-3449, 2011.

8 Wade M, Li Y-C and Wahl GM: MDM2, MDMX and p53 in oncogenesis and cancer therapy. Nat Rev Cancer 13: 83-96, 2013.

9 Hitzenbichler F, Stoehr CG, Rogenhofer M, Wieland WF, Ruemmele P, Hartmann A and Stoehr R: Mdm2 SNP309 Gvariant is associated with invasive growth of human urinary bladder cancer. Pathobiology 81: 53-59, 2014.

10 Danovi D, Meulmeester E, Pasini D, Migliorini D, Capra M, Frenk R, de Graaf P, Francoz S, Gasparini P, Gobbi A, Helin K, Pelicci PG, Jochemsen AG and Marine JC: Amplification of Mdmx (or Mdm4) directly contributes to tumor formation by inhibiting p53 tumor suppressor activity. Mol Cell Biol 24: 5835-5843, 2004.

11 Lenos K, Grawenda AM, Lodder K, Kuijjer ML, Teunisse AFAS, Repapi E, Grochola LF, Bartel F, Hogendoorn PCW, Wuerl P, Taubert H, Cleton-Jansen A-M, Bond GL and Jochemsen AG: Alternate splicing of the p53 inhibitor HDMX offers a superior prognostic biomarker than p53 mutation in human cancer. Cancer Res 72: 4074-4084, 2012.

12 Ramos YF, Stad R, Attema J, Peltenburg LT, van der Eb AJ and Jochemsen AG: Aberrant expression of HDMX proteins in tumor cells correlates with wild-type p53. Cancer Res 61: 1839-1842, 2001.

13 Garcia D, Warr MR, Martins CP, Brown Swigart L, Passegue E and Evan GI: Validation of MdmX as a therapeutic target for reactivating p53 in tumors. Genes Dev 25: 1746-1757, 2011.

14 Salvi S, Calistri D, Gurioli G, Carretta E, Serra L, Gunelli R, Zoli W and Casadio V: Copy number analysis of 24 oncogenes: MDM4 identified as a putative marker for low recurrence risk in non muscle invasive bladder cancer. Int J Mol Sci 15: 1245812468, 2014.

15 Riemenschneider MJ, Knobbe CB and Reifenberger G: Refined mapping of 1q32 amplicons in malignant gliomas confirms MDM4 as the main amplification target. Int J Cancer 104: 752$757,2003$.

16 Bartel F, Schulz J, Böhnke A, Blümke K, Kappler M, Bache M, Schmidt H, Würl P, Taubert H and Hauptmann S: Significance of HDMX-S (or MDM4) mRNA splice variant overexpression and HDMX gene amplification on primary soft tissue sarcoma prognosis. Int J Cancer 117: 469-475, 2005.

17 Prodosmo A, Giglio S, Moretti S, Mancini F, Barbi F, Avenia N, Di Conza G, Schünemann HJ, Pistola L, Ludovini V, Sacchi A,
Pontecorvi A, Puxeddu E and Moretti F: Analysis of human MDM4 variants in papillary thyroid carcinomas reveals new potential markers of cancer properties. J Mol Med 86: 585-596, 2008.

18 Bohmann K, Hennig G, Rogel U, Poremba C, Mueller BM, Fritz P, Stoerkel S and Schaefer K-L: RNA extraction from archival formalin-fixed paraffin-embedded tissue: a comparison of manual, semiautomated, and fully automated purification methods. Clin Chem 55: 1719-1727, 2009.

19 Koutras A, Kalogeras KT, Wirtz RM, Alexopoulou Z, Bobos M, Zagouri F, Veltrup E, Timotheadou E, Gogas H, Pentheroudakis G, Pisanidis N, Magkou C, Christodoulou C, Bafaloukos D, Papakostas P, Aravantinos G, Pectasides D, Kalofonos HP and Fountzilas G: Evaluation of the prognostic significance of HER family mRNA expression in high-risk early breast cancer: a Hellenic Cooperative Oncology Group (HeCOG) validation study. J Transl Med 13: 171, 2015.

20 Tramm T, Sørensen BS, Overgaard J and Alsner J: Optimal reference genes for normalization of qRT-PCR data from archival formalin-fixed, paraffin-embedded breast tumors controlling for tumor cell content and decay of mRNA. Diagn Mol Pathol 22: 181-187, 2013.

21 Choi W, Porten S, Kim S, Willis D, Plimack ER, HoffmanCensits J, Roth B, Cheng T, Tran M, Lee I-L, Melquist J, Bondaruk J, Majewski T, Zhang S, Pretzsch S, Baggerly K, Siefker-Radtke A, Czerniak B, Dinney CPN and McConkey DJ: Identification of distinct basal and luminal subtypes of muscleinvasive bladder cancer with different sensitivities to frontline chemotherapy. Cancer Cell 25: 152-165, 2014.

22 Wang L, Feng C, Ding G, Ding Q, Zhou Z, Jiang H and Wu Z: Ki67 and TP53 expressions predict recurrence of non-muscleinvasive bladder cancer. Tumour Biol 35: 2989-2995, 2014.

23 Bakkar AA, Wallerand H, Radvanyi F, Lahaye J-B, Pissard S, Lecerf L, Kouyoumdjian JC, Abbou CC, Pairon J-C, Jaurand MC, Thiery J-P, Chopin DK and de Medina SGD: FGFR3 and TP53 gene mutations define two distinct pathways in urothelial cell carcinoma of the bladder. Cancer Res 63: 8108-8112, 2003.

24 Shariat SF, Bolenz C, Karakiewicz PI, Fradet Y, Ashfaq R, Bastian PJ, Nielsen ME, Capitanio U, Jeldres C, Rigaud J, Müller SC, Lerner SP, Montorsi F, Sagalowsky AI, Cote RJ and Lotan Y: p53 expression in patients with advanced urothelial cancer of the urinary bladder. BJU Int 105: 489-495, 2010.

25 Parant J, Chavez-Reyes A, Little NA, Yan W, Reinke V, Jochemsen AG and Lozano G: Rescue of embryonic lethality in Mdm4-null mice by loss of Trp53 suggests a nonoverlapping pathway with MDM2 to regulate p53. Nat Genet 29: 92-95, 2001.

26 Veerakumarasivam A, Scott HE, Chin S-F, Warren A, Wallard MJ, Grimmer D, Ichimura K, Caldas C, Collins VP, Neal DE and Kelly JD: High-resolution array-based comparative genomic hybridization of bladder cancers identifies mouse double minute 4 (MDM4) as an amplification target exclusive of MDM2 and TP53. Clin Cancer Res 14: 2527-2534, 2008.

27 Linke K, Mace PD, Smith CA, Vaux DL, Silke J and Day CL: Structure of the MDM2I[sol]IMDMX RING domain heterodimer reveals dimerization is required for their ubiquitylation in trans. Cell Death \& Differentiation Cell Death Differ 15: 841-848, 2008.

28 Pellegrino M, Mancini F, Lucà R, Coletti A, Giacchè N, Manni I, Arisi I, Florenzano F, Teveroni E, Buttarelli M, Fici L, Brandi R, Bruno T, Fanciulli M, D’Onofrio M, Piaggio G, Pellicciari R, Pontecorvi A, Marine JC, Macchiarulo A and Moretti F: 
Targeting the MDM2/MDM4 Interaction interface as a promising approach for $\mathrm{p} 53$ reactivation therapy. Cancer Res 75 : 4560-4572, 2015.

29 Bond GL, Hu W, Bond EE, Robins H, Lutzker SG, Arva NC, Bargonetti J, Bartel F, Taubert H, Wuerl P, Onel K, Yip L, Hwang S-J, Strong LC, Lozano G and Levine AJ: A single nucleotide polymorphism in the MDM2 promoter attenuates the p53 tumor suppressor pathway and accelerates tumor formation in humans. Cell 119: 591-602, 2004.

30 Knappskog S and Lønning PE: MDM2 promoter SNP285 and SNP309; phylogeny and impact on cancer risk. Oncotarget 2: 251-258, 2011.

31 Horikawa Y, Nadaoka J, Saito M, Kumazawa T, Inoue T, Yuasa $\mathrm{T}$, Tsuchiya N, Nishiyama H, Ogawa $\mathrm{O}$ and Habuchi T: Clinical implications of the MDM2 SNP309 and p53 Arg72Pro polymorphisms in transitional cell carcinoma of the bladder. Oncol Rep 20: 49-55, 2008.

32 Yurakh AO, Ramos D, Calabuig-Fariñas S, López-Guerrero JA, Rubio J, Solsona E, Romanenko AM, Vozianov AF, Pellin A and Llombart-Bosch A: Molecular and immunohistochemical analysis of the prognostic value of cell-cycle regulators in urothelial neoplasms of the bladder. Eur Urol 50: 506-515, 2006
33 Lianes P, Orlow I, Zhang ZF, Oliva MR, Sarkis AS, Reuter VE and Cordon-Cardo C: Altered patterns of MDM2 and TP53 expression in human bladder cancer. J Natl Cancer Inst 86 : 1325-1330, 1994.

$34 \mathrm{Yu}$ Q, Li Y, Mu K, Li Z, Meng Q, Wu X and Wang Y: Amplification of $\mathrm{Mdmx}$ and overexpression of MDM2 contribute to mammary carcinogenesis by substituting for p53 mutations. Diagn Pathol 2014.

35 Matijasevic Z, Krzywicka-Racka A, Sluder G and Jones SN: MdmX regulates transformation and chromosomal stability in p53-deficient cells. Cell Cycle 7: 2967-2973, 2008.

36 Matijasevic Z, Steinman HA, Hoover K and Jones SN: MdmX promotes bipolar mitosis to suppress transformation and tumorigenesis in p53-deficient cells and mice. Mol Cell Biol 28: 1265-1273, 2008.
Received August 6, 2016

Revised August 27, 2016

Accepted August 29, 2016 